\title{
Profound Loss of Layer II Entorhinal Cortex Neurons Occurs in Very Mild Alzheimer's Disease
}

\author{
Teresa Gómez-Isla, ${ }^{1}$ Joseph L. Price, ${ }^{2}$ Daniel W. McKeel Jr., ${ }^{2}$ John C. Morris, ${ }^{2}$ John H. Growdon, ${ }^{1}$ and \\ Bradley T. Hyman' \\ ${ }^{1}$ Neurology Service, Massachusetts General Hospital, Boston, Massachusetts 02114, and 2Departments of Anatomy and \\ Neurobiology, Pathology and Neurology, and the Alzheimer's Disease Research Center, Washington University, \\ St. Louis, Missouri 63110
}

The entorhinal cortex (EC) plays a crucial role as a gateway connecting the neocortex and the hippocampal formation. Layer II of the EC gives rise to the perforant pathway, the major source of the excitatory input to the hippocampus, and layer IV receives a major hippocampal efferent projection. The EC is affected severely in Alzheimer disease (AD), likely contributing to memory impairment. We applied stereological principles of neuron counting to determine whether neuronal loss occurs in the $E C$ in the very early stages of $A D$. We studied 20 individuals who at death had a Clinical Dementia Rating (CDR) score of 0 (cognitively normal), 0.5 (very mild), 1 (mild), or 3 (severe cognitive impairment). Lamina-specific neuronal counts were carried out on sections representing the entire EC. In the cognitively normal $(C D R=0)$ individuals, there were $\sim 650,000$ neurons in layer II, 1 million neurons in layer IV, and 7 million neurons in the entire EC. The number of neurons remained constant between 60 and 90 years of age. The group with the mildest clinically detectable dementia $(C D R=0.5)$, all of whom had sufficient neurofibrillary tangles (NFTs) and senile plaques for the neuropathological diagnosis of $A D$, had $32 \%$ fewer $E C$ neurons than controls. Decreases in individual lamina were even more dramatic, with the number of neurons in layer II decreasing by $60 \%$ and in layer IV by $40 \%$ compared with controls. In the severe dementia cases $(C D R=3)$, the number of neurons in layer II decreased by $\sim 90 \%$, and the number of neurons in layer IV decreased by $\sim 70 \%$ compared with controls. Neuronal number in AD was inversely proportional to NFT formation and neuritic plaques, but was not related significantly to diffuse plaques or to total plaques. These results support the conclusion that a marked decrement of layer II neurons distinguishes even very mild AD from nondemented aging.

Key words: entorhinal cortex; stereology; neuronal loss; perforant pathway; Alzheimer's disease; aging
Distinguishing Alzheimer's disease (AD) from normal aging has been a recurring nosological and diagnostic problem (Drachman, 1983; Berg, 1988; Morris et al., 1991). From a clinical point of view, the idea that mild memory loss is a common concomitant of aging raises a theoretical model whereby $\mathrm{AD}$ and aging lie on a continuous spectrum (Bartus et al., 1982; Brayne and Calloway, 1988). According to this idea, AD represents exaggerated aging rather than a true "disease" (Drachman, 1994).

Controversy also exists about whether aging and AD represent a neuropathological continuum or are dichotomous (Terry et al., 1981, 1987; Coleman and Flood, 1987; West et al., 1994). Neurofibrillary tangles (NFTs) and senile plaques (SPs), the two chief neuropathological hallmarks of $\mathrm{AD}$, are reported to occur frequently in aging brains (Tomlinson et al., 1968; Dayan, 1970; Ball, 1977; Arriagada et al., 1992a; Bouras, 1993). NFTs are nearly universal in the hippocampal formation in nondemented individuals over the age of $\sim 60$ years, and the number increases with age (Price et al., 1991; Arriagada et al., 1992a; Price, 1993). Numerous

\footnotetext{
Received March 26, 1996; revised April 25, 1996; accepted May 1, 1996.

This work was supported in part by Grants AG05134, AG08487, AG03991, and AG05681. We thank the physicians and staff of the Clinical Core of the Alzheimer's Disease Research Center (ADRC) of Washington University for the subject evaluations, the Neuropathology Core of the ADRC for postmortem diagnosis of Alzheimer's disease, Dr. Elizabeth Grant of the ADRC Biostatistics Core for clinical data analysis, and Mr. Hieu Van Luu for the histological preparation of the sections.

Correspondence should be addressed to Bradley T. Hyman, Neurology Service, Warren 407, Massachusetts General Hospital, Boston, MA 02114.

Copyright (C) 1996 Society for Neuroscience $0270-6474 / 96 / 164491-10 \$ 05.00 / 0$
}

SPs also may be present in many nondemented individuals (Delaere et al., 1990). The distribution of NFTs and SPs in various brain regions in the elderly matches the pattern of hierarchical vulnerability seen in AD and Down syndrome (Mann et al., 1987; Arnold et al., 1991; Price et al., 1991; Arriagada et al., 1992a,b; Hof et al., 1995; Hyman et al., 1995). On the basis of these observations, it can be argued that only quantitative differences separate $\mathrm{AD}$ from healthy aging and, thus, $\mathrm{AD}$ might represent an accelerated aging process.

An alternative point of view is that $\mathrm{AD}$ and normal aging are not a continuum but are two well-differentiated processes from both clinical and pathological perspectives. One of the most difficult and crucial issues in this problem is the clinical determination of normality as distinguished from very mild or even presymptomatic disease. Recent studies suggest that in truly healthy aging, intellectual performance remains unimpaired over time, whereas sustained decline of even modest proportions may represent a pathological condition rather than representing benign senescence (Roth, 1986; Morris and Fulling, 1988; Morris et al., 1991, 1996; Linn et al., 1995). This second point of view implies that a line of demarcation based on qualitative differences separates the pathological condition of AD from healthy aging.

In an attempt to distinguish these two possibilities, we compared quantitative neuropathological features of individuals known to be cognitively normal before death, individuals with the earliest clinically detectable signs of dementia of the Alzheimer type, and individuals with well-established AD. We used stereo- 
Table 1. Neuronal counts in the entire EC for control subjects

\begin{tabular}{|c|c|c|c|c|c|c|}
\hline Case & CDR & Age & Sex & $\begin{array}{l}\text { Number of } \\
\text { neurons } \times \\
10^{6}\end{array}$ & $\begin{array}{l}\text { Reference } \\
\text { volume } \\
\left(\mathrm{cm}^{3}\right)\end{array}$ & $\begin{array}{l}\text { Neuronal density } \\
\text { (neurons/ } \\
\mathrm{mm}^{3} \times 10^{3} \text { ) }\end{array}$ \\
\hline 1 & 0 & 60 & $\mathrm{~F}$ & 6.18 & 1.04 & 59 \\
\hline 2 & 0 & 61 & $\mathrm{M}$ & 7.14 & 1.30 & 55 \\
\hline 3 & 0 & 70 & $\mathrm{~F}$ & 6.89 & 0.90 & 77 \\
\hline 4 & 0 & 73 & $\mathrm{~F}$ & 8.70 & 0.96 & 91 \\
\hline 5 & 0 & 75 & $\mathrm{~F}$ & 5.89 & 0.80 & 74 \\
\hline 6 & 0 & 76 & $\mathrm{~F}$ & 7.64 & 1.17 & 65 \\
\hline 7 & 0 & 80 & M & 5.06 & 0.83 & 61 \\
\hline 8 & 0 & 83 & $\mathrm{M}$ & 8.46 & 0.99 & 85 \\
\hline 9 & 0 & 83 & $\mathrm{~F}$ & 6.90 & 0.84 & 82 \\
\hline 10 & 0 & 89 & $\mathrm{M}$ & 6.26 & 0.91 & 69 \\
\hline Average & & 75 & & 6.91 & 0.97 & 72 \\
\hline $\mathrm{SD}$ & & 9 & & 1.13 & 0.15 & 12 \\
\hline
\end{tabular}

logically based cell-counting techniques to assess the structural integrity of the entorhinal cortex (EC). The EC was chosen because it is highly selectively vulnerable in AD (Hyman et al., 1984, 1986; Arnold et al., 1991; Braak and Braak, 1991; Price et al., 1991; Arriagada et al., 1992a; Fukutani et al., 1995; Solodkin and Van Hoesen, 1996). Moreover, layers II and IV of the EC are among the first regions affected with tangles in Down syndrome and in normal aging (Mann and Esiri, 1989; Price et al., 1991; Arriagada et al., 1992b; Hyman et al., 1995). The EC lies in a critical path in neural systems related to memory; it receives afferents from widespread association and limbic areas, projects to the dentate gyrus of the hippocampal formation, receives afferents from the hippocampus, and sends afferents back to association neocortex (Rosene and Van Hoesen, 1987; Zola-Morgan et al., 1994). Damage of the EC and related structures is associated with memory impairment (Leonard et al., 1995). Because memory impairment frequently is the earliest symptom of $\mathrm{AD}$, we reasoned that neuropathological changes and neuronal loss in the EC might contribute to memory impairment at the very mild stages of AD.

\section{MATERIALS AND METHODS}

We performed neuronal counts in the EC from 20 individuals whose cognitive status before death was known. Clinical and neuropathological observations from these cases have been published previously (Morris et al., 1991, 1996; Price et al., 1991; Berg et al., 1993; McKeel et al., 1993; Price, 1993). All cases were evaluated clinically in the Memory and Aging Project of the Washington University Alzheimer's Disease Research Center (ADRC).

Of the 20, $9(2 \mathrm{CDR}=0,3 \mathrm{CDR}=0.5,4 \mathrm{CDR}=3)$ were part of a longitudinal study and had undergone enrollment procedures that included validated inclusionary and exclusionary criteria to diagnose dementia of the Alzheimer type (Berg et al., 1982; Morris et al., 1988) and assess cognitive status according to the Washington University Clinical Dementia Rating (CDR) (Morris, 1993). Control subjects met all exclusionary criteria but were not demented. Recruitment, entry characteristics, and assessment methods have been described previously (Berg et al., 1982). In brief, subjects were recruited from the greater St. Louis metropolitan community and examined by experienced physicians at entry and at $\sim 12-18$ month intervals thereafter. Of the nine cases, seven were assessed within 1 year of their death and one was assessed 2 years before death. The ninth case (rated CDR $=0$ ) was assessed 6.4 years before death; in this case, an extensive retrospective interview with close relatives shortly after the subject's death was used to confirm the CDR. Of note, the two $\mathrm{CDR}=0$ individuals were among the oldest examined, ages 80 and 89 . In three of the four cases with a CDR score $=0.5$, there was slight initial disagreement between the examining clinicians and the
Table 2. Neuronal counts per lamina for control subjects

\begin{tabular}{|c|c|c|c|c|c|c|}
\hline \multirow[b]{2}{*}{ Case } & \multirow[b]{2}{*}{ CDR } & \multicolumn{5}{|c|}{ Number of neurons $\times 10^{6}$} \\
\hline & & Layer I & Layer II & Layer III & Layer IV & Layers V, VI \\
\hline 1 & 0 & 0.031 & 0.54 & 3.03 & 0.79 & 1.80 \\
\hline 2 & 0 & 0.059 & 0.65 & 3.09 & 1.40 & 1.93 \\
\hline 3 & 0 & 0.025 & 0.79 & 3.32 & 1.24 & 1.51 \\
\hline 4 & 0 & 0.024 & 0.65 & 4.71 & 1.23 & 2.09 \\
\hline 5 & 0 & 0.011 & 0.70 & 3.18 & 0.78 & 1.22 \\
\hline 6 & 0 & 0.044 & 0.81 & 4.19 & 0.86 & 1.74 \\
\hline 7 & 0 & 0.043 & 0.31 & 2.69 & 0.91 & 1.11 \\
\hline 8 & 0 & 0.019 & 0.68 & 3.88 & 1.22 & 2.66 \\
\hline 9 & 0 & 0.022 & 0.61 & 3.92 & 0.94 & 1.41 \\
\hline 10 & 0 & 0.022 & 0.73 & 3.24 & 0.95 & 1.32 \\
\hline Average & & 0.03 & 0.65 & 3.52 & 1.03 & 1.68 \\
\hline $\mathrm{SD}$ & & 0.014 & 0.14 & 0.62 & 0.22 & 0.47 \\
\hline
\end{tabular}

reviewer; these cases were rated as $\mathrm{CDR}=0 / 0.5$ to denote "questionable" dementia. These cases were treated as CDR $=0.5$ subjects, because clinical evaluation raised the question of "very mild" dementia.

The standardized clinical assessment included semistructured interviews with the subject and a collateral source (usually the spouse or other close relative) and several brief cognitive scales, including the collateral source-derived Dementia Scale of Blessed (Blessed et al., 1968), the Aphasia Battery (Faber-Langendoen et al., 1988), and the Short Portable Mental Status Questionnaire (Pfeiffer, 1975). Symptoms of depression in the subject were solicited both by self-report and from the collateral source at each time of evaluation (Knesevich et al., 1983). The assessment protocol provided information sufficient for the clinician to determine the presence of dementia and, when present, to stage dementia severity according to the CDR, in which a score of 0 indicates no cognitive impairment and a score of $0.5,1,2$, or 3 indicates very mild, mild, moderate, or severe dementia (Hughes et al., 1982; Morris, 1993). The CDR is a global measure of dementia severity and is scored solely on clinical information without reference to psychometric performance. Reports by the collateral informant of functional decline in the subject's performance of usual activities can indicate accurately the earliest symptoms of AD at the CDR 0.5 stage (Morris, 1991). At entry and every 2

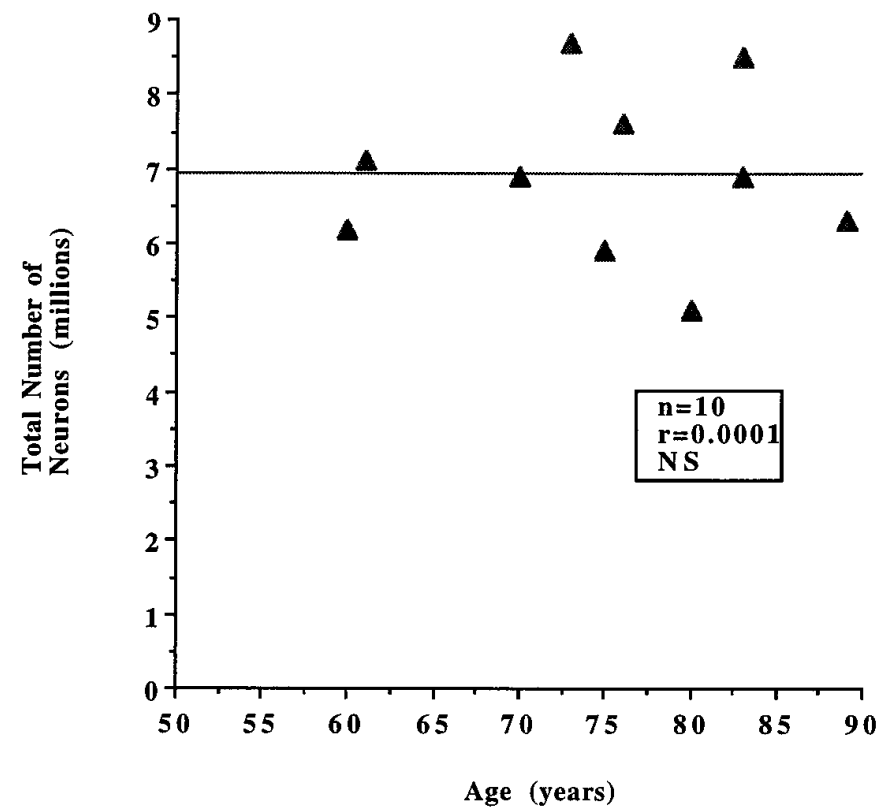

Figure 1. No statistically significant differences in the total number of neurons in the $\mathrm{EC}$ were observed in the nondemented group $(\mathrm{CDR}=0$; $n=10)$ according to age ( $r=0.0001, p=0.98, \mathrm{NS})$. 


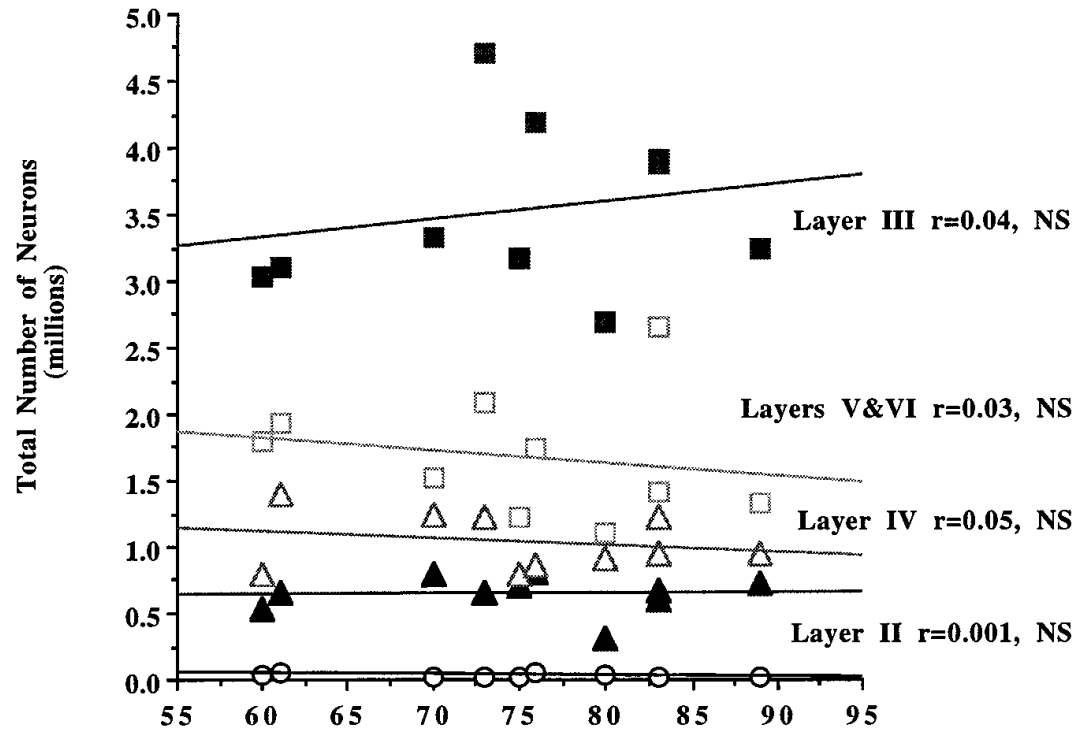

Age (years)
Figure 2. No statistically significant differences in the number of neurons per layer in the EC were observed in the nondemented group $(\mathrm{CDR}=0 ; n=10)$ according to age (layer II, $r=0.001, p=0.91$; layer III, $r=0.04, p=0.57$; layer IV, $r=0.05, p=0.54$; layers $\mathrm{V}, \mathrm{VI}, r=0.03, p=$ $0.60, \mathrm{NS})$. years thereafter, the collateral and subject interview portions of the assessment were videotaped for review by another clinician who provided a second CDR score.

The remaining 11 cases $(8 \mathrm{CDR}=0,1 \mathrm{CDR}=0.5,1 \mathrm{CDR}=1,1$ $\mathrm{CDR}=3$ ) were evaluated postmortem only. Their cognitive status before death was established with a structured Retrospective Collateral Dementia (RCD) interview with a close relative, administered via telephone by a Memory and Aging Project physician. This interview is similar to the collateral interviews used in the premortem assessments and has been validated, allowing a CDR score to be assigned with reliability (Davis et al., 1991). All CDR determinations were made before neuropathological examination.

From the clinical assessments, the 20 subjects included in this study were subdivided into two groups. The AD group included the 10 clinically demented individuals rated $\mathrm{CDR}=0.5$ to 3 (mean age $\pm \mathrm{SD}=84.2 \pm$ 9.9 years; range, 67-95 years). All of them had a subsequent neuropathological diagnosis of definite AD (Khachaturian, 1985; Mirra et al., 1991). The control group was formed by the 10 individuals who were rated $\mathrm{CDR}=0$ and therefore were believed to be cognitively normal (mean age $\pm \mathrm{SD}=75 \pm 9$ years; range $60-89$ years). Although some of these cases had a few NFTs in the EC or scattered SPs, none of them met criteria for AD by neuropathological examination (Khachaturian, 1985; Mirra et al., 1991).

The brains were fixed within $36 \mathrm{hr}$ after death by immersion in buffered

\section{Table 3. Neuronal counts in the entire EC for AD subjects}

\begin{tabular}{|c|c|c|c|c|c|c|}
\hline Case & CDR & Age & Sex & $\begin{array}{l}\text { Total number } \\
\text { of neurons } \\
\times 10^{6}\end{array}$ & $\begin{array}{l}\text { Reference } \\
\text { volume } \\
\left(\mathrm{cm}^{3}\right)\end{array}$ & $\begin{array}{l}\text { Neuronal density } \\
\text { (neurons/ } \\
\mathrm{mm}^{3} \times 10^{3} \text { ) }\end{array}$ \\
\hline 1 & 0.5 & 85 & $\mathrm{M}$ & 4.83 & 1 & 48 \\
\hline 2 & 0.5 & 86 & M & 4.45 & 0.71 & 63 \\
\hline 3 & 0.5 & 95 & $\mathrm{~F}$ & 4.73 & 0.66 & 72 \\
\hline 4 & 0.5 & 95 & $\mathrm{~F}$ & 4.81 & 0.70 & 69 \\
\hline 5 & 1 & 86 & $\mathrm{~F}$ & 5.82 & 0.79 & 74 \\
\hline 6 & 3 & 67 & M & 2.47 & 0.38 & 65 \\
\hline 7 & 3 & 71 & $\mathrm{~F}$ & 2.47 & 0.40 & 60 \\
\hline 8 & 3 & 77 & $\mathrm{M}$ & 3.08 & 0.50 & 62 \\
\hline 9 & 3 & 85 & $\mathrm{~F}$ & 0.90 & 0.14 & 64 \\
\hline 10 & 3 & 95 & $\mathrm{~F}$ & 2.84 & 0.56 & 51 \\
\hline Average & & 84.2 & & 3.64 & 0.59 & 63 \\
\hline SD & & 9.9 & & 1.51 & 0.24 & 8 \\
\hline
\end{tabular}

$10 \%$ formalin for 2 weeks before the sectioning at $1 \mathrm{~cm}$ intervals in the coronal plane. For neuropathological diagnosis, tissue blocks were selected from standardized regions of the left cerebral hemisphere. Tissue blocks were embedded in paraffin, sectioned at $6 \mu \mathrm{m}$, and stained with a battery of conventional and immunohistochemical stains (McKeel et al., 1993; Mirra et al., 1994; Morris et al., 1996). Blinded counts of total diffuse, neuritic, and cored SPs and NFTs were made in midfrontal, superior temporal, and inferior parietal lobule neocortex, in hippocampal area CA1, and in the EC, using modified Bielschowsky silver methods (Berg et al., 1993; McKeel et al., 1993).

For neuronal counts and other research purposes, large blocks $(\sim 3$ $\times 5 \mathrm{~cm}$ ) were taken from the right cerebral hemisphere for serial sectioning. The blocks included the ventral half of the brain from the orbital cortex, rostrally, through the basal forebrain, amygdala, and insula, including the entire hippocampal formation and adjacent temporal neocortex, caudally. The blocks were soaked in a cryoprotective solution ( $30 \%$ sucrose or $10 \%$ glycerin) and serial sectioned at $50 \mu \mathrm{m}$ on a freezing microtome. All sections, including a complete series through the hippocampus and EC, were collected and divided into series of 1 in 22. Adjacent series were stained using the Nissl and Bielschowsky methods and immunohistochemically with antibodies against paired helical filaments (Price et al., 1991).

To count neurons within the EC, the boundaries of this cortical area were marked on Nissl-stained sections through its full rostro-caudal extent. The description of the EC by Amaral and Insausti (1990) was used to define the medial and lateral boundaries of the EC. No attempt to identify EC subdivisions was made. Following a systematically random scheme and based on stereological unbiased techniques, five $50-\mu \mathrm{m}$-thick sections were selected, taken at equally spaced intervals $(3 \mathrm{~mm})$ along the entire length of the EC on each brain (Gundersen, 1992; West, 1993). The volume of the entire EC (reference volume) in each brain was estimated according to the principle of Cavalieri (Cavalieri, 1966), using the Bioquant Image Analysis System (Nashville, TN) that allows the delineation of the layers on each section. To ensure that the estimation was unbiased, the first section plane was placed randomly within the first interval length (West and Gundersen, 1990). Within each section, a systematically random sampling scheme was applied to count neurons. The number of neurons in the entire EC and in each of its laminae was estimated by using $\sim 1500$ optical dissectors in each case. Each optical dissector was a $50 \times 100$ micrometer sampling box with extended exclusion lines. This intensive sampling was necessary to obtain an adequate representation of each of the layers, because the laminar densities in the EC are markedly heterogeneous. Using a $100 \times$ oil-immersion objective lens, neurons that had a visible nucleolus were counted if they were not present in the initial plane of focus but came into the focus as the optical plane moved through the tissue. Detailed descriptions of these techniques have been presented elsewhere (West and Gundersen, 1990). The appro- 


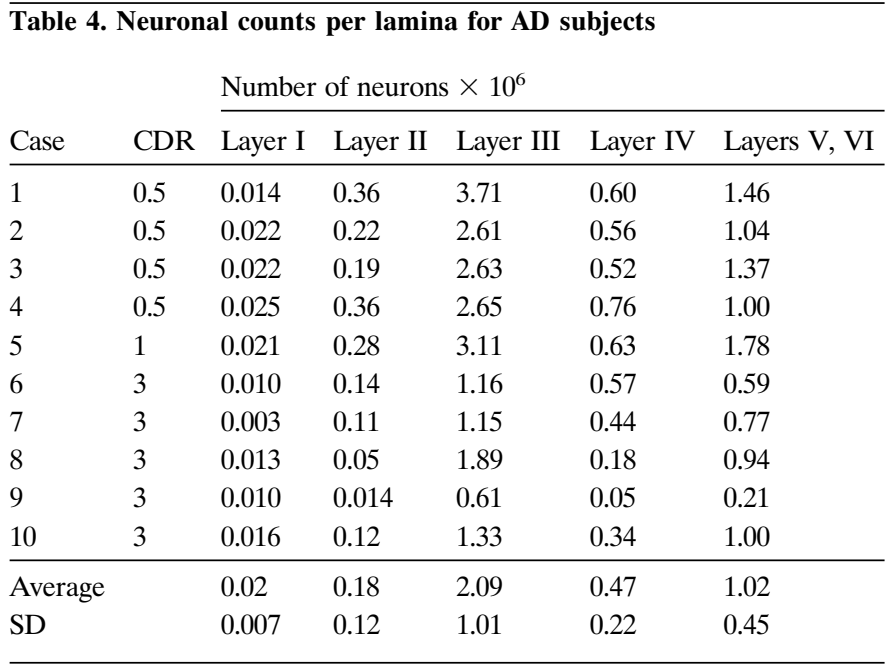

priateness of the sampling scheme chosen was evaluated by calculating the precision of the estimates made in each individual, expressed as the coefficient of error (CE) as described previously (West and Gundersen, 1990). In all cases, the CE was $<0.06$, suggesting that a minimal amount of variance in the counts is from the technique. The estimation of total number was performed by multiplying the volume density of neurons in the layers by the volume of the layers. All counts were carried out by one examiner (T.G.I.) without knowledge of the age, gender, or neuropathogical status of the material being analyzed.

NFTs and SPs were mapped from the immunostained or Bielschowskystained $50 \mu \mathrm{m}$ frozen sections with the aid of a microscope digitizer coupled to a computer, as described previously (Price et al., 1991). The computerized maps then were transferred to a computer-aided design program, and the boundaries of brain structures were added. The density of tangles and plaques within the EC as a whole was measured by outlining the EC and then measuring the area and counting the number of items within it.

Statistical comparison of neuron number (in each layer) to age among controls was by linear regression analyses. Comparison of neuronal number, density, and volume in each layer in AD compared with controls was by ANOVA. Comparison of neuronal number to NFT density and SP density was made by rank ordering the cases and comparing the rank orders by Spearman rank correlation coefficient, because the NFT and SP counts were obtained at a representative level rather than throughout the entire anterior-posterior extent of the EC. Differences were considered to be significant if $p<0.05$.

\section{RESULTS}

\section{Neuron number in the EC is unchanged in cognitively normal aging}

We first examined whether a change in neuronal number occurs with increasing age in individuals who are believed to be cognitively normal $(\mathrm{CDR}=0)$. When the number of neurons in the entire EC and in each lamina was compared within this group $(n=10)$, no statistically significant differences were observed according to age (Tables 1,2). The total number of neurons in the EC, as well as neuronal densities and volumes, remained stable between the sixth and ninth decades (Fig. 1). When the same parameters were estimated per layer, again the analysis showed no significant change in number of neurons with increasing age in the nondemented group (Fig. 2).

\section{Neuron number in the EC is decreased substantially in $A D$}

The averages of the total number of neurons in the entire EC and in each lamina, along with neuronal densities and reference volumes corresponding to each $\mathrm{CDR}$ category in the $\mathrm{AD}$ group, are shown in Tables 3 and 4. A highly significant difference was

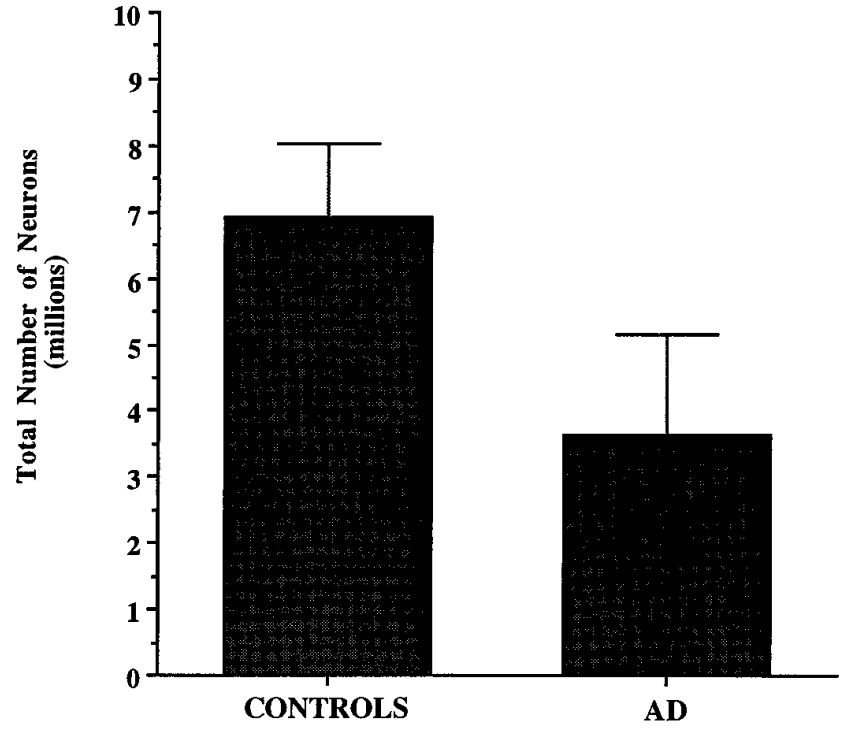

Figure 3. The average total number of neurons in the EC was reduced by $48 \%$ in the $\mathrm{AD}$ group $(n=10)$ when compared with the nondemented group $(n=10)(p<0.001)$.

observed when the AD group as a whole was compared with the nondemented group. The average total number of neurons in the $\mathrm{EC}$ was $3.64 \pm 1.51 \times 10^{6}$ in $\mathrm{AD}$ versus $6.91 \pm 1.13 \times 10^{6}$ in controls. The difference represents a $48 \%$ reduction in total number of EC neurons in the AD group compared with controls $(p<0.001)$ (Fig. 3). The volume of the EC in AD was $\sim 40 \%$ less than controls $(p<0.001)$ (Fig. 4). When volume densities were compared, only layer II reached statistical significance, $4.4 \times 10^{3}$ versus $7.3 \times 10^{3}$ neurons $/ \mathrm{mm}^{3}(p<0.001)$. No significant differences were found in terms of neuronal densities in the remaining layers, suggesting that density measures are not as sensitive as estimates of total neuronal number in identifying neuronal loss.

Significantly fewer neurons were present in each layer in the AD group (Fig. 5). The degree of neuronal change in layer II was

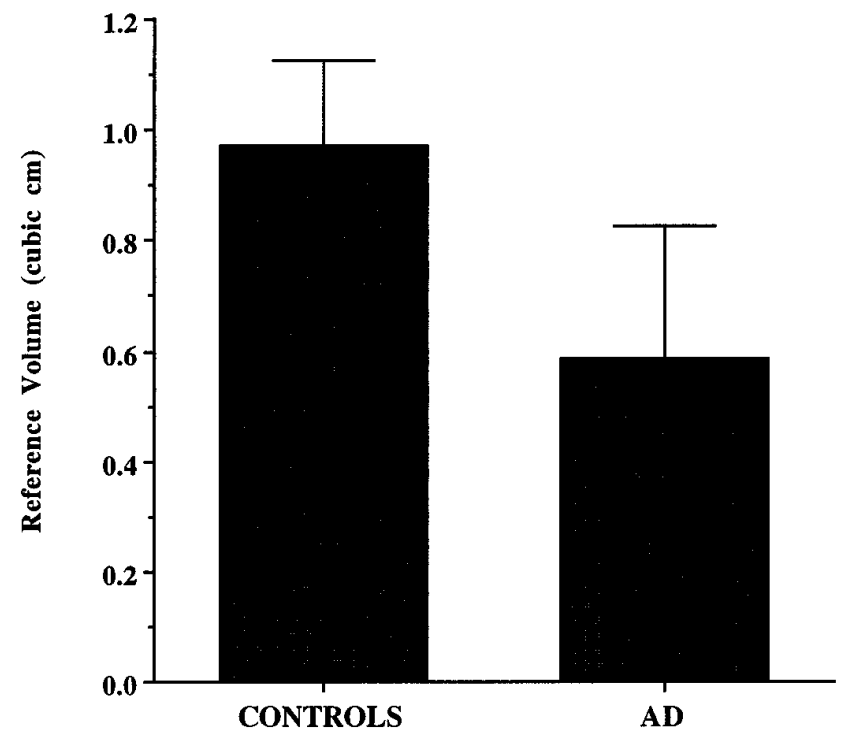

Figure 4. The volume of the EC was reduced by $40 \%$ in the AD group $(n=10)$ when compared with the nondemented group $(n=10)$ $(p<0.001)$. 


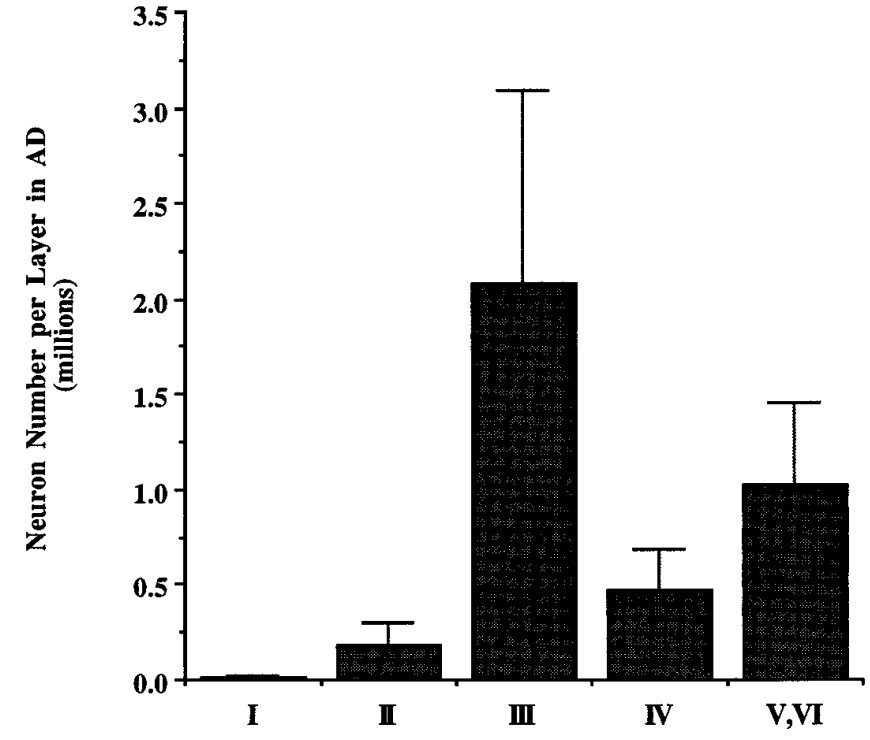

Figure 5. Significant decreases in neuronal number were present in all layers of $\mathrm{EC}$ in the $\mathrm{AD}$ brains $(n=10)$ when compared with the nondemented group $(n=10)$. Decrease in cell number in the $\mathrm{AD}$ group was highest in layer II compared with other layers (layer II, 72\%, $p<$ 0.001 ; layer III, $41 \%, p<0.01$; layer IV, $55 \%, p<0.001$; layers V, VI, $40 \%, p<0.01)$

substantially larger than in any other layer (layer II, 72\%, $p<$ 0.001 ; layer III, $41 \%, p<0.01$; layer IV, $55 \%, p<0.001$; layers $\mathrm{V}$, VI, $40 \%, p<0.01)$.

\section{Neuronal number decreased most dramatically in layers II and IV in very mild AD}

Neuronal number decreased from $68 \%$ of control values in the $\mathrm{CDR}=0.5$ subgroup to $31 \%$ of control in the $\mathrm{CDR}=3$ subgroup (Fig. 6). The same correlation between the severity of neuronal loss and CDR score was observed when individual laminae were analyzed in AD brains. Layer II followed by layer IV showed the highest and earliest rates of neuronal depopulation. For example, in layer II there were $647,360 \pm 143,220$ in controls, decreasing $57 \%$ to $282,290 \pm 90,460$ neurons in the individuals with the mildest cognitive deterioration $(\mathrm{CDR}=0.5, n=4)$, and decreasing further to $85,130 \pm 50,260$, only $13 \%$ of control, in the most severe cases $(\mathrm{CDR}=3, n=5)$. In layer IV, a $41 \%$ decrease from the number of neurons in the CDR $=0$ group was estimated in the $\mathrm{CDR}=0.5$ subgroup, and a $69 \%$ decrease was observed in the $\mathrm{CDR}=3$ subgroup. The remaining layers all together (I, III, V,

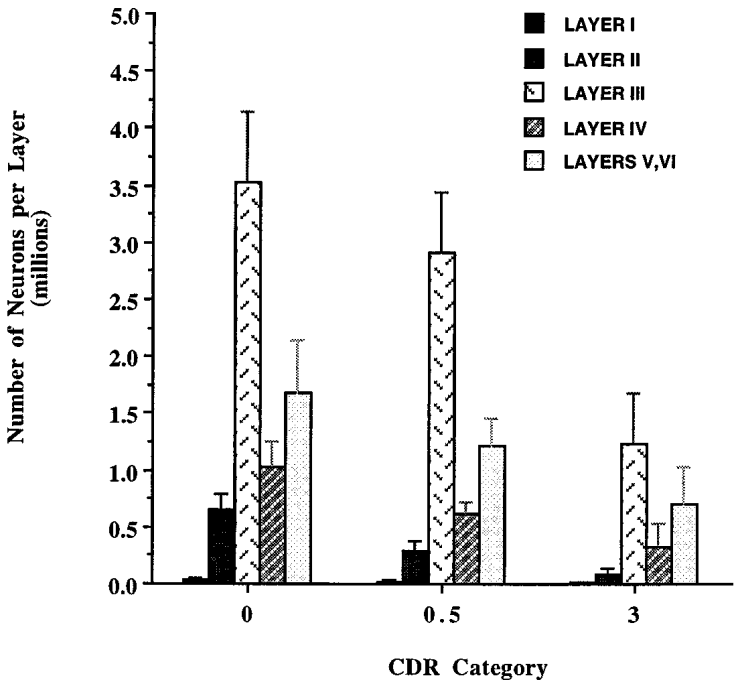

Figure 7. The number of neurons in the $\mathrm{EC}$ of $\mathrm{AD}$ brains $(n=10)$ compared with CDR $=0$ controls $(n=10)$, negatively correlated with clinical severity of dementia in all layers. Layers II and IV, in particular, showed the highest and earliest changes. In layer II, a difference of $57 \%$ was estimated in the CDR $=0.5$ subgroup $(n=4)$ and $87 \%$ in the $\mathrm{CDR}=$ 3 subgroup $(n=5)$. In layer IV, differences of 41 and $69 \%$, respectively, were estimated in the same CDR subgroups.

and VI) showed a $25 \%$ decrease from control levels in the CDR $=$ 0.5 subgroup and $63 \%$ decrease from control levels in the CDR $=$ 3 subgroup (Fig. 7).

\section{Neuronal changes paralleled NFTs and plaque neuritic formation but not amyloid deposition}

We also compared EC neuron number to NFT and SP densities in the same cortex (Tables 5, 6). Figure 8 represents maps of NFTs in the EC and CA1 zone of the hippocampus of representative cases of each $\mathrm{CDR}$ category $(\mathrm{CDR}=0,0.5$, and 3$)$. In general, NFTs were predominant in layers II and IV with fewer numbers in III, V, and VI, whereas SPs were more scattered, although amyloid plaques tended to occur in layer III. A significant negative correlation between the number of neurons and the degree of NFTs $(Z=-2.24, p=0.02)$ and neuritic plaques was observed $(Z=-2.44, p=0.01)$ (Figs. 9 and $10 b)$, but no significant correlation was found between either of these two parameters and the number of total SPs $(Z=-0.17, p=0.86, \mathrm{NS})$ or diffuse plaque subpopulations in the same area $(Z=1.72, p=0.09)$ (Fig. 10a,c).

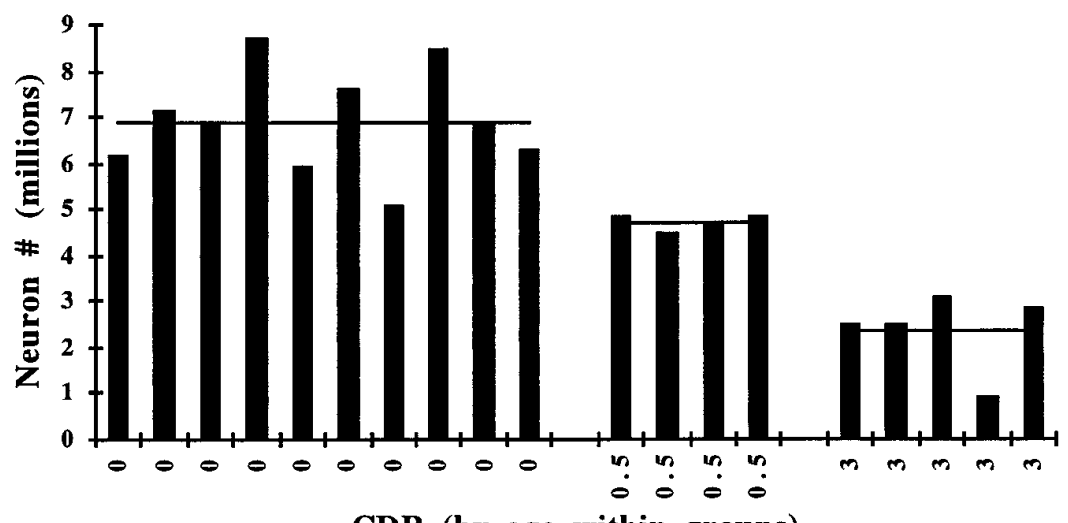

CDR (by age within groups)
Figure 6. The number of neurons in the $\mathrm{EC}$ in the $\mathrm{AD}$ group $(n=10)$ compared with CDR $=0$ controls $(n=10)$, correlated with the clinical severity of dementia. The difference increased from $32 \%$ in the CDR $=0.5$ subgroup $(n=$ 4) to $69 \%$ in the $\mathrm{CDR}=3$ subgroup $(n=5)$. 
Table 5. Tangle and plaque densities for control subjects

\begin{tabular}{|c|c|c|c|c|c|c|c|c|}
\hline \multirow[b]{3}{*}{ Case } & \multirow[b]{3}{*}{ Sex } & \multirow[b]{3}{*}{ Age } & \multicolumn{6}{|c|}{ Plaque and tangle densities (no. $/ \mathrm{mm}^{2}$ ) } \\
\hline & & & \multicolumn{2}{|c|}{$\begin{array}{l}\text { Hippocampus } \\
\text { (CA1) }\end{array}$} & \multicolumn{2}{|c|}{ Entorhinal } & \multicolumn{2}{|c|}{$\begin{array}{l}\text { Lateral } \\
\text { temporal } \\
\text { cortex }\end{array}$} \\
\hline & & & SP & NFT & SP & NFT & SP & NFT \\
\hline \multicolumn{9}{|c|}{ CRD-0 } \\
\hline 1 & $\mathrm{~F}$ & 60 & 0 & 0.4 & 0 & 1.5 & 0 & 0 \\
\hline 2 & M & 61 & 0 & $\mathrm{~N} / \mathrm{A}$ & 0 & $\mathrm{~N} / \mathrm{A}$ & 0 & $\mathrm{~N} / \mathrm{A}$ \\
\hline 3 & $\mathrm{~F}$ & 70 & 0 & 14.4 & 2.3 & 0 & 0 & 0 \\
\hline 4 & $\mathrm{~F}$ & 73 & 0 & $\mathrm{~N} / \mathrm{A}$ & 0 & $\mathrm{~N} / \mathrm{A}$ & 0 & $\mathrm{~N} / \mathrm{A}$ \\
\hline 5 & $\mathrm{~F}$ & 75 & 0 & 0.1 & 0 & 8.7 & 0 & 0 \\
\hline 6 & $\mathrm{~F}$ & 76 & 0.1 & 16.8 & 1.1 & 3.7 & 0.6 & 0.1 \\
\hline 7 & $\mathrm{M}$ & 80 & 0 & 5.2 & 0 & 16.1 & 0.1 & 0.1 \\
\hline 8 & $\mathrm{M}$ & 83 & 0 & 1.3 & 0 & 3.4 & 0.4 & 0 \\
\hline 9 & $\mathrm{~F}$ & 83 & 0.3 & 0.1 & 7.1 & 0.9 & 5.0 & 0 \\
\hline 10 & M & 89 & 0 & 35.3 & 0.5 & 37.6 & 0.2 & 0.1 \\
\hline
\end{tabular}

N/A, Not available.

\section{DISCUSSION}

The individuals included in this study were highly selected cases. Half of them were carefully assessed cognitively intact subjects, and four others had very mild stages of dementia. Although the number and age span of the cases limit generalization of the findings, the following four major conclusions can be drawn from the data: (1) There are $\sim 7$ million neurons in the adult human EC. No significant loss of neurons in the EC is detectable in cognitively normal subjects between the sixth and ninth decades of life. (2) There is, by contrast, a very severe neuronal loss in the EC even in very mild $\mathrm{AD}$ cases that are at the threshold for clinical detection of dementia. This neuronal loss is so marked that it must have started well before onset of clinical symptoms. (3) The most dramatic neuronal loss selectively targets layers II and IV of EC, paralleling the known susceptibility of cells in these layers for NFT formation. As the clinical severity of dementia progresses,

Table 6. Tangle and plaque densities for AD subjects

\begin{tabular}{|c|c|c|c|c|c|c|c|c|}
\hline \multirow[b]{3}{*}{ Case } & \multirow[b]{3}{*}{ Sex } & \multirow[b]{3}{*}{ Age } & \multicolumn{6}{|c|}{ Plaque and tangle densities (no./ $\mathrm{mm}^{2}$ ) } \\
\hline & & & \multicolumn{2}{|c|}{$\begin{array}{l}\text { Hippocampus } \\
\text { (CA1) }\end{array}$} & \multicolumn{2}{|c|}{ Entorhinal } & \multicolumn{2}{|c|}{$\begin{array}{l}\text { Lateral } \\
\text { temporal } \\
\text { cortex }\end{array}$} \\
\hline & & & SP & NFT & SP & NFT & SP & NFT \\
\hline \multicolumn{9}{|c|}{ AD CDR- 0.5} \\
\hline 1 & M & 85 & 6.7 & 6.5 & 5.9 & 17.7 & 17.7 & 0.4 \\
\hline 2 & M & 86 & 7.7 & 55.7 & 19.1 & 42.4 & 18.3 & 2.4 \\
\hline 3 & $\mathrm{~F}$ & 95 & 0.2 & 9.3 & 6.5 & 29.7 & 13.7 & 0.2 \\
\hline 4 & $\mathrm{~F}$ & 95 & 2.6 & 21.5 & 13.3 & 48.4 & 25.0 & 5.0 \\
\hline \multicolumn{9}{|c|}{ AD CDR-1 } \\
\hline 5 & $\mathrm{~F}$ & 86 & 9.7 & 6.1 & 14.3 & 4.2 & 5.7 & 0.0 \\
\hline \multicolumn{9}{|c|}{ AD CDR-3 } \\
\hline 6 & M & 67 & 12.2 & 66.4 & 15.7 & 110.6 & 37.9 & 52.5 \\
\hline 7 & $\mathrm{~F}$ & 71 & 8.8 & 143.0 & 11.1 & 111.1 & 22.0 & 53.2 \\
\hline 8 & M & 77 & 7.4 & 12.7 & 9.7 & 25.4 & 45.0 & 0.3 \\
\hline 9 & $\mathrm{~F}$ & 85 & 6.2 & 40.5 & 16.3 & N/A & 16.9 & 33.7 \\
\hline 10 & $\mathrm{~F}$ & 95 & 10.4 & 43.1 & 15.7 & 42.0 & 22.9 & 9.3 \\
\hline
\end{tabular}

$\overline{\mathrm{CDR} \text {, Clinical dementia rating, where CDR-0.5 indicates questionable dementia; }}$ N/A, not available. the remaining layers of EC also are affected. (4) The degree of neuronal loss in the EC parallels the incidence of NFTs and neuritic plaques, but not to diffuse plaques without neuritic changes.

Although individual variations were observed in our study, the neuronal population in the EC, one of the regions that is known to be vulnerable to AD changes, remained stable in nondemented individuals between the sixth and ninth decades. Falkai et al. (1988) reported comparable results in a group of 11 younger control cases. Trillo and Gonzalo (1992) also found no significant neuronal loss in the lateral area of the EC in 17 cases from age 35 to 75 years. Although these two latter studies used counting procedures and sampling schemes that differ from ours, their results are congruent with the data presented in this series and support the conclusion that substantial neuronal loss does not occur in the EC during healthy aging. Lippa et al. (1992), using optical dissectors in single sections, showed no loss in EC in 10 nondemented cases between ages 42 and 87 years, although a 31-year-old subject had higher numbers and a 97-year-old subject had lower numbers. Losses in layer II were over $90 \%$ in nine AD patients, similar to our data. Losses of $\sim 75 \%$ of EC neurons in $\mathrm{AD}$ were reported by Fukutani et al. (1995). In contrast to these data, Heinsen et al. (1994) reported an age-related neuronal loss of $26-39 \%$ in EC among 22 individuals between 18 and 86 years of age. The apparent discrepancy with the present results could be in part attributable to case-selection procedures that may have resulted in contamination by unsuspected early $\mathrm{AD}$ cases. In addition, Heinsen et al. counted only partial thickness of thick histological sections, potentially creating variability attributable to differential shrinkage during the staining and mounting procedures of frozen sections.

Based on the same stereological unbiased methods used in the present study, West et al. (1994) recently reported no change in neuron number in several hippocampal subfields in normal aging, although they did detect neuronal loss in the dentate hilus and subiculum. This pattern of loss contrasted with loss primarily in the CA1 hippocampal region in AD brains. Both our results and those of West et al. (1994) reinforce the idea that there is a selective pattern of neuronal vulnerability in $\mathrm{AD}$ that contributes to memory impairments: CA1 zone of the hippocampus (West et al., 1994) and layers II and IV of EC (our study). The fact that neuronal loss does not occur in these regions during the normal aging process is consistent with the hypothesis that $\mathrm{AD}$ and aging are not part of a continuous spectrum and suggests that normal aging and $\mathrm{AD}$ can be differentiated from a neuropathological perspective.

The marked EC alterations in layers II and IV in clinically mild AD highlight the relative selective vulnerability of these lamina. It seems likely that these changes disrupt the recently described modular organization of the EC and, hence, its contribution to memory-related neural systems (Solodkin and Van Hoesen, 1996). It is important to note that NFTs in these clinically mild cases also occur in the CA1-subiculum of the hippocampus, the perirhinal cortex, inferior temporal gyrus, the amygdala and posterior parahippocampal gyri, cholinergic basal forebrain, and dorsal raphe, although in general to a less dramatic extent than layer II of the EC (Arriagada et al., 1992a). It is likely that neuronal loss occurs in these areas as well, and that the net result of these multiple lesions in memory-related structures accounts for the impairment in explicit memory function that occurs as an early symptom in AD (Locascio et al., 1995). In contrast to the marked loss of neurons in EC in patients with very mild dementia, how- 


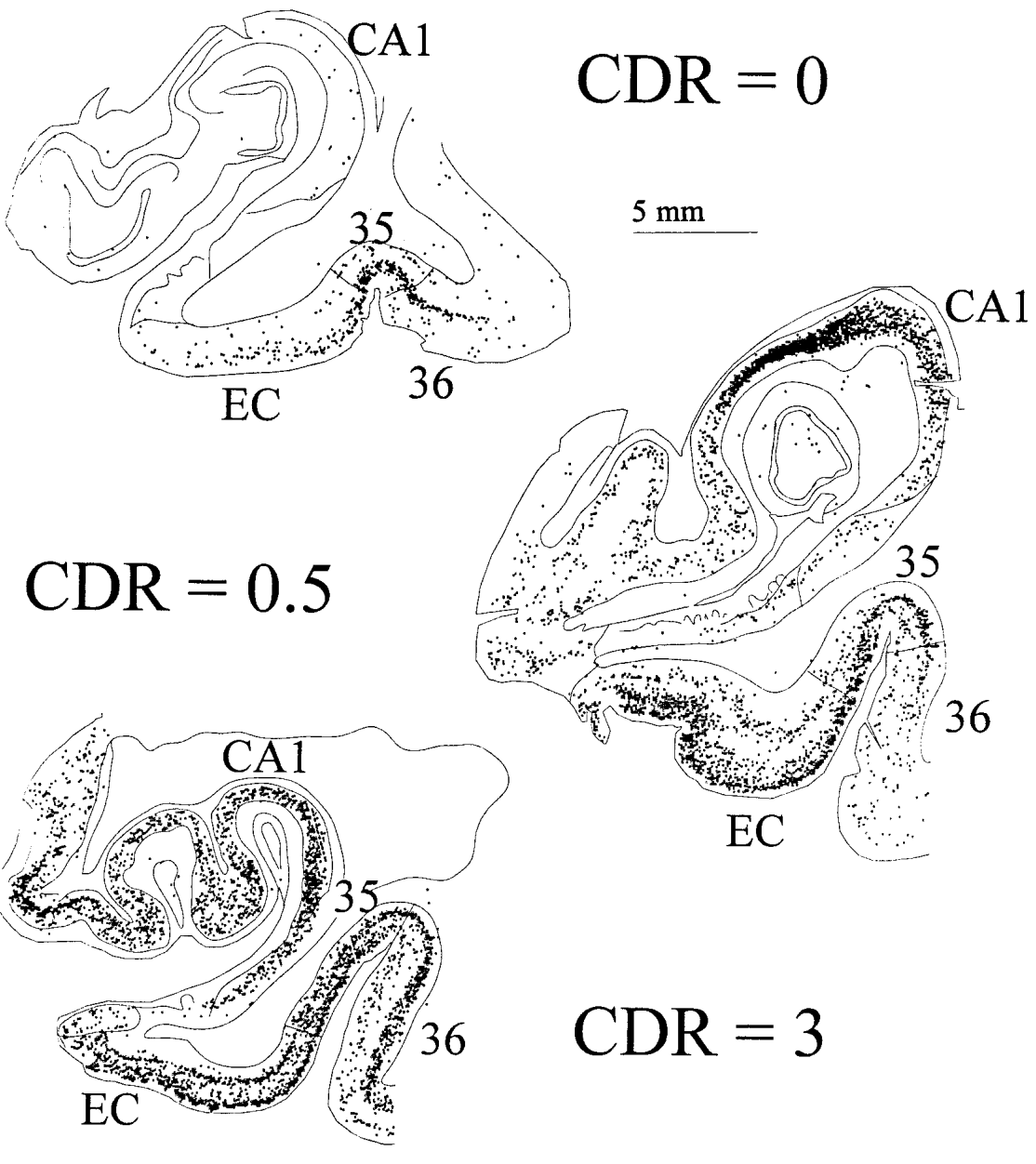

Figure 8. The topographical distribution of NFTs assessed by PHF-1 immunostaining (Price et al., 1991) in the $\mathrm{EC}$ and $\mathrm{CA} 1$ zone of the hippocampus is illustrated in each $\mathrm{CDR}$ category $(\mathrm{CDR}=0,0.5$, and 3$)$.

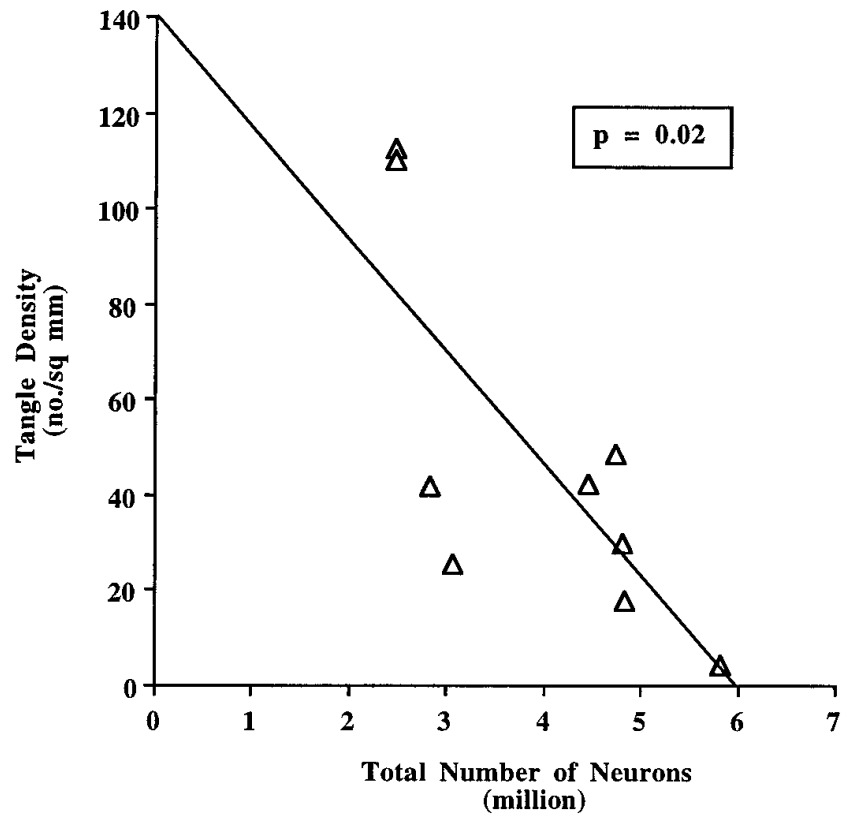

Figure 9. The rank order of cases for NFT density in the EC was negatively correlated with the number of neurons (Spearman rank correlation test $n=$ $17, Z=3.40, p<0.001)$. We also calculated the relationship between the rank order of NFT densities and the number of neurons in the $\mathrm{AD}$ group alone $(n=9, Z=-2.24, p=0.02)$. The graph represents data from nine $\mathrm{AD}$ brains. In one case, the PHF-1 immunostaining for NFTs was not available. ever, our recent studies in the superior temporal sulcus (STS) association cortex suggest that the STS does not undergo neuronal loss until a much later point in the disease process, when clinical symptoms of a more advanced dementia are present (Hyman et al., 1995). In accord with this, preliminary study of the STS in the $\mathrm{CDR}=0.5$ patients in this study shows no difference in STS neuron number compared with nondemented controls. Ultimately, the number of STS neurons decreases by $\sim 50 \%$ in advanced AD (Hyman et al., 1995).

The fact that the number of layer II neurons in the EC is fewer than half of the control neuronal population at a time when only mild or questionable clinical symptoms of $\mathrm{AD}$ become apparent supports the idea of a large functional reserve in memory-related neural systems and is consistent with a presymptomatic phase of AD. Clinical studies have suggested that subtle cognitive changes might be present for years before dementia can be detected reliably (Linn et al., 1995). It is likely that a threshold of neuronal loss in the entorhinal region, along with accompanying alterations in other memory-related structures, must be reached before memory impairment becomes detectable clinically. On the other hand, neuronal loss in layer II may well be maximal at a time when global dementia rating scales reflect a moderate level of impairment. The concept of such a substantial loss of EC neurons before $\mathrm{AD}$ symptoms occur may be analogous to the observation that very substantial neuronal losses are present in the substantia nigra before extrapyramidal symptoms become apparent in Parkinson's disease (Hirsch et al., 1988). 

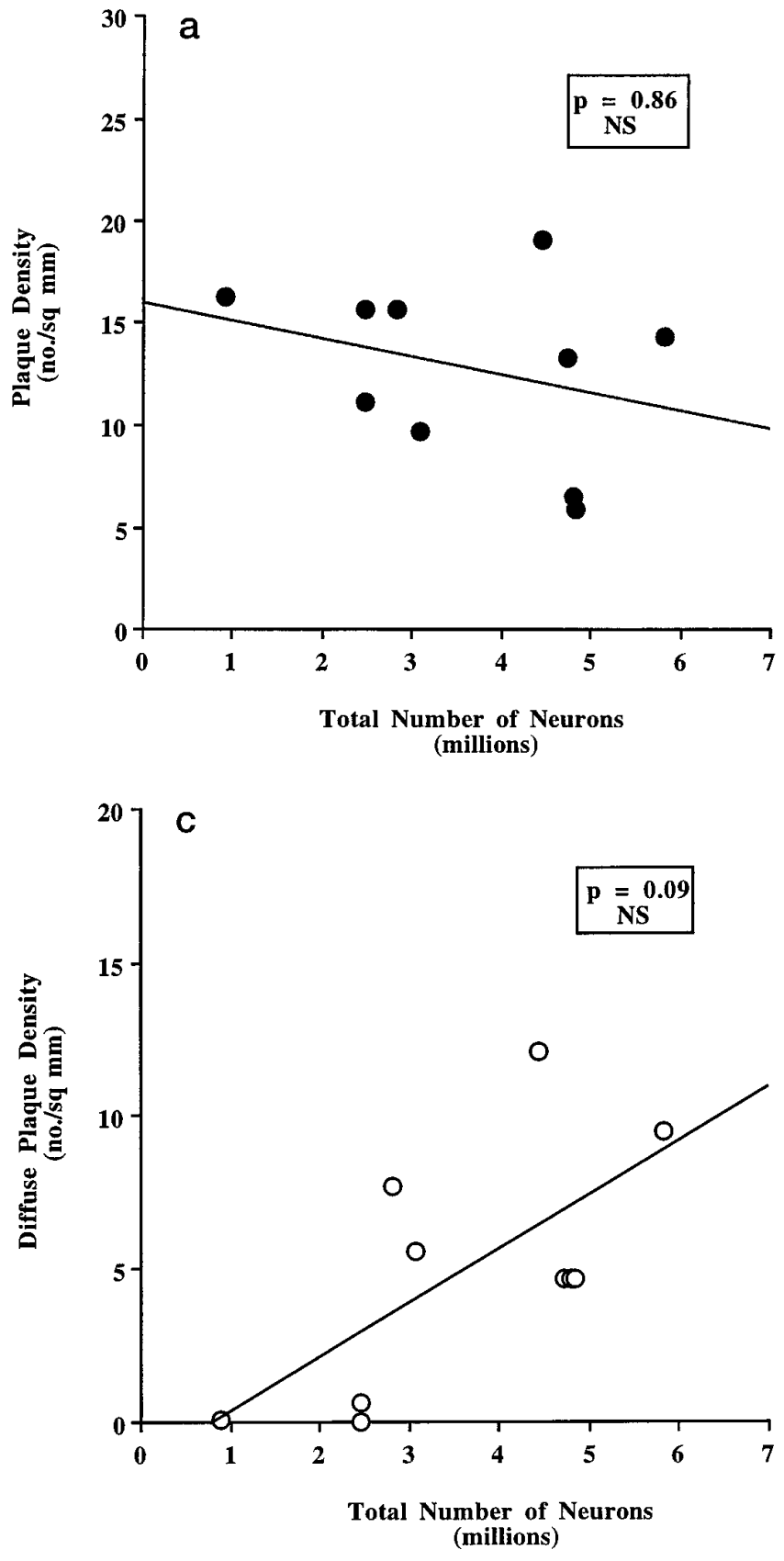

The neuronal loss in the entire EC is accompanied by a parallel reduction of its volume, pointing to an associated loss of the neuropil, presumably including synapses. Absolute synaptic loss is more difficult than neuronal number to analyze, in part because of the plastic renormalization of synaptic densities and the enlargement of the remaining synaptic profiles (Coleman and Flood, 1988; De Kosky and Scheff, 1990). However, there is a close correlation between loss of synapses and synaptophysin immunostaining and cognitive deterioration (Terry et al., 1991), and perhaps the neuronal loss we highlight contributes to the synaptic alterations that have been observed in the hippocampal formation (Hamos et al., 1989; Cabalka et al., 1992; Samuel et al., 1994).

In addition to the estimate of total neurons in the EC, we calculated the results obtained when we used only a single section (at the level of the uncal hippocampus) from each case. The same trends are apparent even sampling from only a single section, but

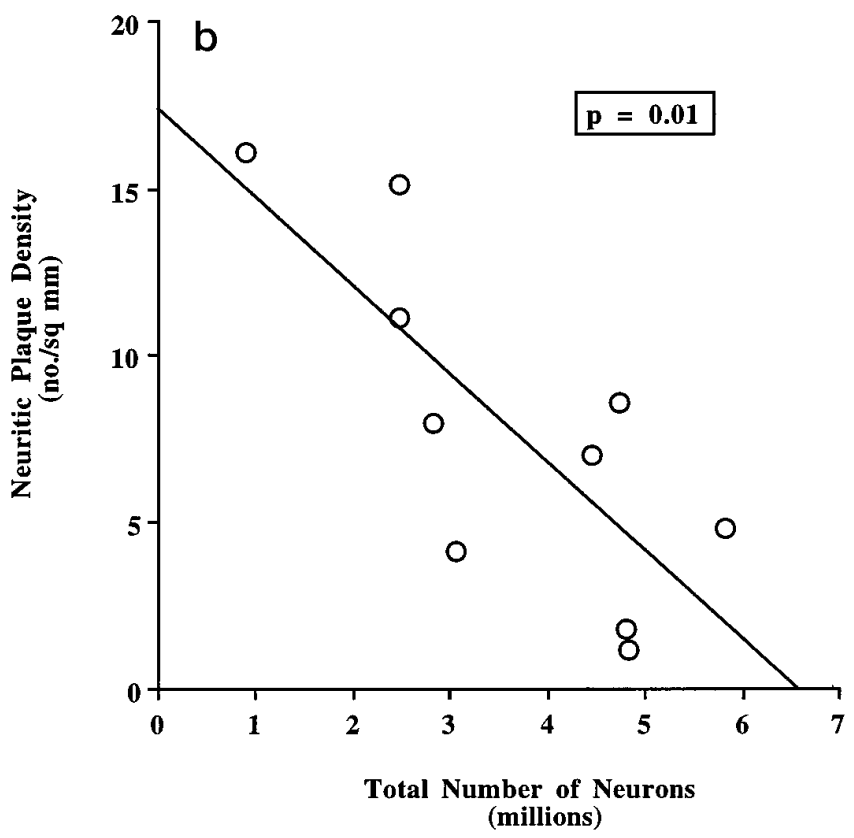

Figure 10. $a$, Total SP density (neuritic and cored plus diffuse plaques), as assessed from a Bielschowsky-stained section in the EC, did not correlate with number of neurons in AD brains $(n=10)$ (Spearman rank correlation test; $Z=-0.17, p=0.86$, NS). $b$, The density of neuritic and cored plaques in the EC of AD brains $(n=10)$, as assessed from a Bielschowsky-stained section, negatively correlated with the number of neurons (Spearman rank correlation test; $Z=$ $-2.44, p=0.01)$. $c$, The density of diffuse plaques in the EC of AD brains $(n=10)$, as assessed from a Bielschowsky-stained section, did not correlate with the number of neurons (Spearman rank correlation test; $Z=1.72, p=0.09$, NS).

because this estimate does not take into account atrophy in the anterior-posterior direction, the degree of loss in the AD cases is underestimated. For example, had we used data from only one section, rather than a $32 \%$ decrement in EC in the CDR 0.5 cases, we would have calculated only a $23 \%$ decrease in comparison to the average of the 10 controls. This result may be of practical use in the design of future stereologically based experiments in human cortices, given the difficulty of obtaining serial sections throughout an entire structure in the human brain.

The results of this study show that the amount of neuronal loss in the EC in AD brains parallels neuritic changes, including tangle formation and neuritic plaques. In contrast, no correlation is found between cell loss and amyloid deposition in diffuse plaques or in total plaques. These observations are in agreement with previous morphometric studies in other brain regions suggesting a strong correlation of NFTs with clinical symptoms, but a less 
strong or no relationship between the number of amyloid SPs and the duration or severity of illness (Price et al., 1991; Terry et al., 1991; Arriagada et al., 1992a; Berg et al., 1993; Bouras et al., 1993; Hyman et al., 1993; Nagy et al., 1995; Gómez-Isla et al., 1996). These observations suggest that a simple and direct correlation between $\mathrm{A} \beta$ deposition and neurotoxicity is unlikely. Given the relationship between tangle formation and cell loss, it is surprising, at first glance, that cell loss does not increase as a function of age, because there is an age-related increase in tangles, in the absence of dementia (Price, 1991; Arriagada et al., 1992b; Price, 1993). However, immunohistochemical stains for NFTs make the presence of several dozen NFTs in a cortical area quite obvious, whereas neuronal loss must be much more substantial before it can be detected.

In summary, we demonstrate that neuronal loss does not occur in the EC in the cognitively intact elderly, whereas there is a selective and very dramatic loss of neurons in the same region even at the mildest stages of dementia in AD. This finding supports a model in which AD and normal aging are not part of a continuum and can be differentiated both anatomically and clinically. The results highlight the need to develop new diagnostic tests to predict the presymptomatic and very mild stages of $\mathrm{AD}$ before massive neuronal loss in select neural populations has occurred, when therapeutic intervention might be most effective.

\section{REFERENCES}

Amaral DG, Insausti R (1990) Hippocampal formation. In: The human nervous system (Paxinos G, ed), pp 19-31. San Diego: Academic.

Arnold SE, Hyman BT, Flory J (1991) The topographical and neuroanatomical distribution of neurofibrillary tangles and neuritic plaques in cerebral cortex of patients with Alzheimer's disease. Cereb Cortex 1:103-116.

Arriagada PV, Growdon JH, Hedley-Whyte ET, Hyman BT (1992a) Neurofibrillary tangles but not senile plaques parallel duration and severity of Alzheimer's disease. Neurology 42:631-639.

Arriagada PV, Marzloff K, Hyman BT (1992b) Distribution of Alzheimer-type pathological changes in nondemented elderly matches the pattern in Alzheimer's disease. Neurology 42:1681-1688.

Ball MJ (1977) Neuronal loss, neurofibrillary tangles and granulovacuolar degeneration in the hippocampus with ageing and dementia. A quantitative study. Acta Neuropathol (Berl) 37:111-118.

Bartus RT, Dean RLI, Beer B, Lippa AS (1982) The cholinergic hypothesis of geriatric memory dysfunction. Science 217:408-414.

Berg L (1988) The clinical dementia rating (CDR). Psychopharmacol Bull 24:637-639.

Berg L, Hughes CP, Coben LA (1982) Mild senile dementia of Alzheimer type: research diagnostic criteria, recruitment, and description of a study population. J Neurol Neurosurg Psychiatry 45:962-968.

Berg L, McKeel Jr DW, Miller JP (1993) Neuropathologic indexes of Alzheimer's disease in demented and nondemented persons aged 80 years and older. Arch Neurol 50:349-358.

Blessed G, Tomlinson BE, Roth M (1968) The association between quantitative measures of dementia and of senile change in the cerebral grey matter of elderly subjects. Br J Psychiatry 114:797-811.

Bouras C, Hof PR, Morrison JH (1993) Neurofibrillary tangle densities in the hippocampal formation in a non-demented population define subgroups of patients with differential early pathological changes. Neurosci Lett 153:131-135.

Braak H, Braak E (1991) Neuropathological staging of Alzheimer related changes. Acta Neuropathol 82:239-259.

Brayne C, Calloway P (1988) Normal ageing, impaired cognitive function and senile dementia of the Alzheimer's type: a continuum? Lancet 1:1265-1267.

Cabalka LM, Hyman BT, Goodlett CR (1992) Alteration in the pattern of nerve terminal protein immunoreactivity in the perforant pathway in Alzheimer's disease and in rats after entorhinal lesions. Neurobiol Aging 13:283-291.

Cavalieri B (1966) Geometria degli indivisibili. Torino: Unione Tipografico, Editrice.
Coleman PD, Flood DG (1987) Neuron numbers and dendritic extent in normal aging and Alzheimer's disease. Neurobiol Aging 8:521-545.

Coleman PD, Flood DG (1988) Is dendritic proliferation of surviving neurons a compensatory response to loss of neighbors in the aging brain? In: Brain injury and recovery (Finger S, Levere TE, Almli CR, Stein DG, eds), pp 235-247. New York: Plenum.

Davis PB, White H, Price JL (1991) Retrospective postmortem dementia assessment. Validation of a new clinical interview to assist neuropathologic study. Arch Neurol 48:613-617.

Dayan AD (1970) Quantitative histological studies in the aged human brain. I. Senile plaques and neurofibrillary tangles in "normal" patients. Acta Neuropathol (Berl) 16:85-94.

DeKosky ST, Scheff SW (1990) Synapse loss in frontal cortex biopsies in Alzheimer's disease: correlation with cognitive severity. Ann Neurol 27:457-464.

Delaere P, Duyckaerts C, Masters C (1990) Large amounts of neocortical beta A4 deposits without neuritic plaques nor tangles in a psychometrically assessed, non-demented person. Neurosci Lett 166:87-93.

Drachman DA (1983) How normal aging relates to dementia: a critique and classification. In: Aging of the brain, Vol 22, Aging (Samuel D, Algeri S, Gershon S, eds), pp 19-31. New York: Raven.

Drachman DA (1994) If we live long enough, will be all demented? Neurology 44:1563-1565.

Faber-Langendoen K, Morris JC, Knesevich JW (1988) Aphasia in senile dementia of the Alzheimer type. Ann Neurol 23:365-370.

Falkai P, Bogerts B, Rozumek M (1988) Limbic pathology in schizophrenia: the entorhinal region: a morphometric study. Biol Psychiatry 24:515-521.

Fukutani Y, Kobayashi K, Nakamura I (1995) Neurons, intracellular and extracellular neurofibrillary tangles in subdivisions of the hippocampal cortex in normal ageing and Alzheimer's disease. Neurosci Lett 200:57-60.

Gómez-Isla T, West HL, Rebeck GW (1996) Clinical and pathological correlates of Apolipoprotein E $\epsilon 4$ in Alzheimer disease. Ann Neurol 39:62-70.

Gundersen HJG (1992) Stereology: the fast lane between neuroanatomy and brain function or still only a tightrope? Acta Neurol Scand 137:8-13.

Hamos JE, DeGennaro LJ, Drachman DA (1989) Synaptic loss in Alzheimer's disease and other dementias. Neurology 39:355-361.

Heinsen H, Henn R, Eisenmenger W (1994) Quantitative investigations on the human entorhinal area: left-right asymmetry and age related changes. Anat Embryol (Berl) 190:181-194.

Hirsch E, Graybiel AM, Agid YA (1988) Melanized dopaminergic neurons are differentially susceptible to degeneration in Parkinson's disease. Nature 334:345-348.

Hof PR, Bierer LM, Perl DP (1992) Evidence of early vulnerability of the medial and inferior aspects of the temporal lobe in an 82-year-old patient with preclinical signs of dementia. Regional and laminar distribution of neurofibrillary tangles and senile plaques. Arch Neurol 49:946-953.

Hof PR, Bouras C, Perl DP (1995) Age-related distribution of neuropathological changes in the cerebral cortex of patients with Down syndrome. Quantitative regional analysis and comparison with Alzheimer's disease. Arch Neurol 52:379-391.

Hughes CP, Berg L, Danzier WL (1982) A new clinical scale for the staging of dementia. Br J Psychiatry 140:566-572.

Hyman BT, Van Hoesen GW, Damasio AR, Barnes CL (1984) Alzheimer's disease: cell specific pathology isolates the hippocampal formation in Alzheimer's disease. Science 225:1168-1170.

Hyman BT, Van Hoesen GW, Kromer LJ, Damasio AR (1986) Perforant pathway changes and the memory impairment of Alzheimer's disease. Ann Neurol 20:472-481.

Hyman BT, Marzloff K, Arriagada PV (1993) The lack of accumulation of senile plaques or amyloid burden in Alzheimer's disease suggests a dynamic balance between amyloid deposition and resolution. J Neuropathol Exp Neurol 52:594-600.

Hyman BT, West HL, Gómez-Isla T (1995) Quantitative neuropathology in Alzheimer's disease: neuronal loss in high-order association cortex parallels dementia. In: Research advances in Alzheimer's disease and related disorders (Iqbal K, Mortimer JA, Winblad B, Wisniewski HM, eds), pp 453-460. New York: Wiley.

Khachaturian ZS (1985) Diagnosis of Alzheimer's disease. Arch Neurol 42:1097-1105. 
Knesevich JW, Martin RL, Berg L, Danziger W (1983) Preliminary report on affective symptoms in the early stages of senile dementia of the Alzheimer type. Am J Psychiatry 140:233-235.

Leonard BW, Amaral DG, Squire LR, Zola-Morgan S (1995) Transient memory impairment in monkeys with bilateral lesions of the entorhinal cortex. J Neurosci 15:5637-5659.

Linn RT, Wolf PA, Bachman DL (1995) The "Preclinical phase" of probable Alzheimer's disease. Arch Neurol 52:485-490.

Lippa CF, Hamos JE, Pulaski-Salo D (1992) Alzheimer's disease and aging: effects on perforant pathway perikarya and synapses. Neurobiol Aging 13:405-411.

Locascio JJ, Growdon JH, Corkin S (1995) Cognitive test performance in detecting, staging, and tracking Alzheimer's disease. Arch Neurol 52:1087-1099.

Mann DM, Esiri MM (1989) The pattern of acquisition of plaques and tangles in the brains of patients under 50 years of age with Down's syndrome. J Neurol Sci 89:169-179.

Mann DMA, Tucker CM, Yates PO (1987) The topographic distribution of senile plaques and neurofibrillary tangles in the brains of nondemented persons of different ages. Neuropathol Appl Neurobiol 13:123-139.

Masliah E, Terry RD, Alford M (1991) Cortical and subcortical patterns of synaptophysin-like immunoreactivity in Alzheimer's disease. Am J Pathol 138:235-246.

McKeel Jr DW, Ball MJ, Price JL (1993) Interlaboratory histopathologic assessment of Alzheimer neuropathology: different methodologies yield comparable diagnostic results. Alzheimer Dis Assoc Disord 7:136-151.

McKhann G, Drachman D, Folstein M (1984) Clinical diagnosis of Alzheimer's disease: report of the NINCDS-ADRDA group under the auspices of Dept. of HHS Task Force on Alzheimer's Disease. Neurology 34:939-944.

Mirra SS, Heyman A, McKeel Jr DW (1991) The consortium to establish a registry for Alzheimer's disease (CERAD). Pt 2. Standardization of the neuropathologic assessment of Alzheimer's disease. Neurology 41:479-486

Mirra SS, Gearing M, McKeel Jr DW (1994) Interlaboratory comparison of neuropathology assessments in Alzheimer's disease: a study of the Consortium to Establish a Registry for Alzheimer's disease (CERAD). J Neuropathol Exp Neurol 53:303-315.

Morris JC (1993) The clinical dementia rating (CDR): current version and scoring rules. Neurology 43:2412-2414.

Morris JC, Fulling K (1988) Early Alzheimer's disease. Diagnostic considerations. Arch Neurol 45:345-349.

Morris JC, McKeel Jr DW, Fulling K (1988) Validation of clinical diagnostic criteria for Alzheimer's disease. Ann Neurol 24:17-22.

Morris JC, McKeel Jr DW, Storandt M (1991) Very mild Alzheimer's disease: informant-based clinical, psychometric, and pathologic distinction from normal aging. Neurology 41:469-478.

Morris JC, Storandt M, McKeel Jr DW (1996) Cerebral amyloid deposition and diffuse plaques in "normal" aging: evidence for presymptomatic and very mild Alzheimer's disease. Neurology, in press.
Nagy Z, Esiri MM, Jobst KA (1995) Relative roles of plaques and tangles in the dementia of Alzheimer's disease: correlations using three sets of neuropathological criteria. Dementia 6:21-31.

Pfeiffer E (1975) A short portable mental status questionnaire for the assessment of organic brain deficit in elderly patients. J Am Geriatr Soc 23:433-441.

Price JL (1993) The relationship between tangle and plaque formation during healthy aging and mild dementia. Neurobiol Aging 14:661-663.

Price JL, Davis PB, Morris JC, White DL (1991) The distribution of tangles, plaques and related immunohistochemical markers in healthy aging and Alzheimer's disease. Neurobiol Aging 12:295-312.

Rosene DL, Van Hoesen GW (1987) The hippocampal formation of the primate. In: The cerebral cortex (Jones EG, ed), pp 345-456. New York: Plenum.

Roth M (1986) The association of clinical and neurological findings and its bearing on the classification and aetiology of Alzheimer's disease. $\mathrm{Br}$ Med Bull 42:42-50.

Samuel W, Masliah E, Hill LR (1994) Hippocampal connectivity and Alzheimer's dementia: effects of synapse loss and tangle frequency in a two-component model. Neurology 44:2081-2088.

Solodkin A, Van Hoesen GW (1996) Entorhinal cortex modules of the human brain. J Comp Neurol 365:610-627.

Steward O (1976) Topographic organization of the projections from the entorhinal area to hippocampal formation of the rat. J Comp Neurol 167:285-314

Storandt M, Hill RD (1989) Very mild senile dementia of the Alzheimer type. II. Psychometric test performance. Arch Neurol 46:383-386.

Terry RD, Peck A, DeTeresa R (1981) Some morphometric aspects of the brain in senile dementia of the Alzheimer type. Ann Neurol 10:184-192.

Terry RD, Masliah E, Salmon DP (1991) Physical basis of cognitive alterations in Alzheimer's disease: synapse loss is the major correlate of cognitive impairment. Ann Neurol 30:572-580.

Tomlinson BE, Blessed G, Roth M (1968) Observations on the brains of non-demented old people. J Neurol Sci 7:331-356.

Trillo L, Gonzalo LM (1992) Ageing of the human entorhinal cortex and subicular complex. Histol Histopathol 7:17-22.

West M (1993) New stereological methods for counting neurons. Neurobiol Aging 14:275-285.

West MJ, Gundersen HJG (1990) Unbiased stereological estimation of the number of neurons in the human hippocampus. J Comp Neurol 296:1-22.

West MJ, Coleman PD, Flood DG, Troncoso JC (1994) Differences in the pattern of hippocampal neuronal loss in normal ageing and Alzheimer's disease. Lancet 344:769-772.

Zola-Morgan S, Squire LR, Ramus SJ (1994) Severity of memory impairment in monkeys as a function of locus and extent of damage within the medial temporal lobe memory system. Hippocampus 4:483-495. 